Article

\title{
Contested Spaces: The Heterotopias of the Victorian Sickroom
}

\author{
Amanda Caleb \\ Department of English, Misericordia University, 301 Lake Street, Dallas, PA 18612, USA; \\ acaleb@misericordia.edu
}

Received: 17 March 2019; Accepted: 16 April 2019; Published: 19 April 2019

\begin{abstract}
Both the invalid and the sickroom pervade the writings of the Victorian period, particularly in fiction, medical guidebooks, and autobiographies. The sickroom is a space that separates the invalid from the healthy space of the house and defines the invalid body as other. However, as a space that is both marginalized and central, the sickroom is molded by the medical and social views of sickness and the individualized experience of illness. This article contextualizes the Victorian sickroom by conceptualizing it through the lens of Foucault's heterotopia of deviation, which represents the medicalized act of dividing practices to physically separate those deemed sick from healthy people and spaces. The sickroom functions as a heterotopia in three ways: physical space created by medical authority; textual space contested through invalid narratives; and bodily space, whereby the sickroom is mapped onto the invalid's body. Thus, the sickroom as heterotopia reveals the contentiousness of invalidism and the limitations of medical authority and power.
\end{abstract}

Keywords: Victorian; invalidism; sickroom; heterotopia; illness; medical

\section{Introduction}

In a review of Harriet Martineau's Life in the Sick-Room, E.Q.S. boldly claimed, "what small community cannot array a host of invalids? What family is without one or more?" (E.Q.S. 1845, p. 163). This assertion is emblematic of the invalid's prominent presence in Victorian fiction, medical literature, and autobiographies, depicting, among other things, physical and/or mental disability (Tankard 2011), delicateness or weakness, especially in women (Byrne 2011), isolation and aloneness (Ablow 2014), and a challenge to medical authority (Winter 1995; Frawley 2004). This last representation reveals the conflict between medical interpretation of invalidism and the invalid's own accounts of illness, which is one of power: While doctors sought to cure and prevent illness, many of the narratives written by those with ongoing illness celebrate the status of invalid as a competing source of authority to that of the doctor.

First-person narratives of invalidism engaged with medical authority and the assertion of the medical gaze by reimagining the sickroom and the invalid within that space. As Maria H. Frawley notes, "the geographic imagery of the nineteenth-century sickroom had an invalid at its center. This figure was endowed with unique powers of observation and insight, powers that seemed naturally to furnish the tools for psychological study" (Frawley 2004, p. 201). Frawley's scholarship is exhaustive and offers the greatest insight into the complexities of the invalid, particularly as an indeterminate figure in Victorian society: weak, yet powerful; central, yet marginalized; and always as a product of the time period.

However, an area that needs further consideration is the relationship between invalid spaces, specifically that of the physical sickroom and that of the textual page, and how that relationship informs our understanding of invalidism itself. Space is a contested area of authority, occupied by the invalid but invaded by medical advice and protocol. As an embodiment of medicine's dividing practices, the sickroom is a domestic space uniquely subject to outside authority and the medical gaze and is an example of Foucault's heterotopia of deviation (Mangion 2015). Derived from the medical term that 
identifies "a part found out of place in the body" (Smith 2014, p. 18), heterotopias are "simultaneously mythic and real contestations of the space in which we live", situated as spaces that are both part of and outside our existing world (Foucault 1984, p. 4). As contrasted to utopias that do not occupy real space, heterotopias are both physical locations and metaphorical constructions. As a heterotopia, the sickroom is a doubly-othered space: it is "made other by the top-down making of places of exclusion [and it is] made other by the deviant groups that live in and appropriate those places" (Cenzatti 2008, p. 77). The invalid's appropriation of the space is not just the transgressive act of writing, particularly for women, but also the act of self-representation that creates a clash of heterotopias and demonstrates how it is a site that is "simultaneously represented, contested, and inverted" (Foucault 1984, p. 3). In reading the sickroom as a heterotopia, I argue that it functions in these three ways: representation through medical authority; contestation through invalid narratives; and inversion through figurative mapping of the sickroom space onto the physical body of the invalid. These heterotopic layers of the sickroom reveal the contested space of invalidism itself.

\section{Physical Heterotopias: Representation through Medical Authority}

In defining heterotopias as physical spaces, Foucault identified six principles: 1 . they exist in all cultures (in some way); 2 . they have specific operations anchored to a specific time; 3 . they house incompatible elements in a single space; 4 . they function within temporal discontinuity; 5 . they are demarcated but accessible, linked to the opening and closing of doors; 6 . they operate in relation to all other spaces (Foucault 1984). These principles map neatly to the sickroom, which: 1. is cross-cultural (in terms of a recovery space); 2 . functions as a specific space for illness; 3 . is a space for the invalid and for visitors and doctors, a sanctuary and a cell; 4 . is a sickroom only when needed (and is usually a bedroom beforehand); 5 . is demarcated by doors and from healthy space, yet accessible to visitors and doctors; 6 . is both central and marginal to the house and its household. It is a space that "exposes every real space, all the sites inside of which human life is partitioned, as still more illusory", i.e., the utopic illusion of healthy space, which can only be known through the heterotopic sickroom (Foucault 1984, p. 8). The sickroom, as a heterotopia of deviation, is constructed by those outside the space or able to leave the space and house those "whose behavior is deviant in relation to the required mean or norm" (Foucault 1984, p. 5). In other words, the sickroom is part of the dividing practice that turn invalids into the subjects of medical power.

From the medical perspective, the sickroom is a space meant to be controlled, thereby denying the sufferer identity and autonomy, and used to maintain social and spatial order. The physical space, as a product of dividing practices, was also an extension of the medical gaze, whereby the invalid was essentially absent from medical accounts of the sickroom, or, if included, was secondary to the space itself. In other words, there was as much concern for how the space which housed the invalid was arranged as for how the invalid was cared for within that space. While some guidelines were beneficial to the health of the invalid, such as notes on ventilation, moisture, and dust, most guides written by the medical community dictated the construction of the sickroom in every facet, beyond the obvious medical benefit. By determining the size and shape ("large, lofty, and, if possible, with a northern aspect"), the furniture arrangement (sparse, and only for medical needs), the material of the furniture (oak whenever possible), and other aspects of the sickroom, these texts denied the invalid any form of agency and instead reasserted medical authority and the privilege of health through a compulsory spatial configuration (Thomson [1841] 1845, p. 113; Gardner 1861). Gardner even goes as far as to suggest constructing a room before it is needed as a sickroom and recommends the thickness of the window bars (a minimum of two inches), the thickness of the door (also two inches), and the thickness of the external walls (at least fourteen inches but preferably eighteen or twenty-one) (Gardner 1861). In one of the most egregious colonization's of patient space, Dr. Anthony Todd Thomson's manual instructs, "if there is a looking-glass in the apartment, in a situation which admits of the patient seeing himself in it as he lies in bed, its place should be changed, or it should be altogether removed from the room" (Thomson [1841] 1845, p. 116). The removal of the mirror acts as a removal of identity and a means of separating the physical body from 
the patient's mental and emotional construction of illness; it also reinforces the medical gaze by only allowing the doctor (and visitors) a view of the invalid's body and condition.

This control extended to the language used to describe both the sickroom and the guides themselves. Dr. Robert Hall Bakewell began his Practical Hints on the Management of the Sickroom by arguing that if authors "put down on paper the directions they are obliged to give verbally to their patients' friends, much more good would be done, than by trying to persuade their unfortunate victims that a science, which it requires years of painful and laborious study to learn, is at the command of any one who chooses to pay 12s. $6 d$. for a handsome octavo volume" (Bakewell 1857, p. 5). The critique levied against home medical guides reasserts medical authority through training, stressing that guidebooks should limit themselves to instruction without explanation: Bakewell assures his readers that "no attempt will be made in little tract to describe the symptoms or treatment of diseases" (Bakewell 1857, p. 5). These disclaimers are part of his broader argument about patients consulting physicians regarding illness, which begs the question: why write the guide in the first place if it just reiterates what doctors would tell their patients? Its existence, and the existence of these other medical guides, was a means of asserting textual authority over illness and the sickroom. This authority is couched in claims of "almost general ignorance which prevails respecting the domestic management of the sickroom" (Thomson [1841] 1845, p. vii) and a topic about which "popular errors are both numerous and dangerous" (Bakewell 1857, p. 47).

The reconfigured bedroom as sickroom represents a disruption to the structure of the Victorian home, not only in the redefinition of space (which spilled into other parts of the house when moving out furniture), but also in how external sources (the doctor and authors of guide books) dictated the configuration of the sickroom. In other words, the bedroom space still enjoyed the semblance of privacy but was imagined and constructed publicly. This blending of private and public speaks to the effect of heterotopias, which "draw us out of ourselves in peculiar ways; they display and inaugurate a difference and challenge the space in which we may feel at home. These emplacements exist out of step and meddle with our sense of interiority" (Johnson 2006, p. 84). Both the interiority of the home and the interiority of the individual are altered through the sickroom: confined to a space that was formerly associated with sleep, sexual relations, and childbirth, the invalid is now restricted to a space that is only defined by ill-health. A space that once some privacy is now on display both literally and textually; at the same time, it was a divided space, one that isolated the invalid and reminded them of their status as other.

\section{Contesting Heterotopias through Text: Invalid Narratives}

In occupying a space defined and created by others, the invalid had limited opportunities to challenge the existence and configuration of that space. While traveling abroad for better health offered a semblance of reprieve from these defined spaces, the domestic sickroom was often exchanged for the foreign sickroom. Physical space may have been difficult to contest but textual space was not, and the popularity and proliferation of the invalid narrative during the Victorian period attests to the invalid's authorial presence (Frawley 2004). It is in this textual reproduction of the sickroom that the invalid can reclaim identity by disrupting the medical structuring of that same space.

Heterotopias, while most often associated with physical space, are also created from linguistic or textual space. In The Order of Things, Foucault asserts that "[heterotopias] secretly undermine language, because they make it impossible to name this and that, because they shatter or tangle common names, because they destroy 'syntax' in advance [ . . they] desiccate speech, stop words in their tracks, contest the very possibility of grammar at its source; they dissolve our myths and sterilize the lyricism of our sentences" (Foucault [1966] 1994, p. xviii). Because heterotopias are contested sites of the real and imagined, the language used to describe them is equally contested and fluid: there is a gap between what is real and what is imagined-what is said and what is meant-but that gap dissolves even as it is created, denying the possibility of difference and differentiation. Contesting these boundaries 
through language, heterotopies offer momentary transgressions, engineered to reveal the faults in the ideological structures of our society.

In writing about the sickroom from their own perspectives, invalid narratives expose the weaknesses of the medical perception of the invalid as separate from and not contributing to healthy society. The very existence of these narratives defied the separation of healthy and sick space through their popularity with a reading public that included both invalids and healthy people; in other words, the act of reading these narratives represents a figurative blurring of boundaries, as invalid narratives were read and housed in both sickrooms and healthy spaces. Moreover, invalid narratives that discussed the physical space of the sickroom sought to undermine the medical authority of how that very space was described. Wilkie Collins, in "Laid Up in Lodgings", reclaims the physical space of the sickroom by way of defying the recommended organization. Instead of large and lofty, his Paris bedroom is small and cramped; instead of located on a ground floor, it is up several flights of stairs; finally, instead of having only one door to enter and exit, it has three (Collins [1856] 1875). The appeal of the space is tied to its functionality for the invalid: As Collins notes, "In sickness, I love and honour the skillful architect who contrived it. In health, I am very much afraid I should never have bestowed so much as a single thought on him" (Collins [1856] 1875, p. 204). Although Collins gives credit to the architect, the space was not deliberately designed for an invalid, which reveals the fluid nature of the space itself. The architect for such a space, then, is Collins, who imagines how the existing space can serve his needs, rather than altering the room per the medical guidelines of the day.

This Parisian sickroom is not just conceived physically; Collins also creates the personal sickroom via language. Unlike medical manuals that instructed other household members on how to arrange the sickroom and treat the invalid-which negates agency of illness-Collins's room is all his own, a fact that he celebrates repeatedly in his account. He calls the space "my toy-castle: My own independent, solitary, miniature mansion", concluding the section: "The one irresistible appeal which my Parisian apartment makes to my sympathies consists in the perfect manner in which it fits my wants and flatters my weaknesses as an invalid" (Collins [1856] 1875, pp. 202, 203). The repetition of my emphasizes Collins's reclamation of the sickroom to suit his individual needs as an invalid, thereby reasserting the singularity of invalid suffering and rejecting a single heterotopia of the sickroom. He further refocuses the space of the sickroom on the invalid, explaining, "I myself am nothing but the centre of a vast medial litter, and the closer the said litter revolves round me the more comfortable I feel" (Collins [1856] 1875, p. 203). While his language might initially read as though he is defined by the medical materials around him, his use of the words "litter", "centre", and "revolves" suggest the opposite: the medical materials are mere odds and ends, which help locate him as the centerpoint of the space itself-these materials only exist in relation to his own importance. The comfort he attributes to this medical litter is derived from his central location, which resituates the invalid as not a passive object of the sickroom but as the active and essential component of the space.

Harriet Martineau, in her well-known Life in the Sick-Room, offers an even more pronounced rejection of the medicalized sickroom. She recommends a room with a view of nature, employing the plural first person to suggest the collective need of all invalids and in contrast to the prescriptions of medicine: "We should have the widest expanse of sky for night scenery. We should have a wide expanse of land or water, for the sake of a sense of liberty, yet more than for variety" (Martineau 1844, p. 45). Her language reveals the text is not written for others and about invalids, but as an invalid and for invalids. Martineau's sickroom is not confined by the precise limitations seen in Gardner's Household Medicine and Sick-Room Guide, but by the expansive possibilities of space without walls, or a sickroom that is more than just a room. Her language, embedded with freedom, not restriction, variety not monotony, and community not isolation, challenges the medical heterotopic limitations of the sickroom space.

This challenge continues with Martineau's argument about the imaginative powers of the invalid, in which she reappropriates the medical gaze: if the medical gaze "alienates the body from the subjective person [ ... to create] the 'patient' as a special type of person", then Martineau's text reclaims the specialness of the patient through the individual's subjective self (Frawley 2004, p. 228-29). This 
subjective self is the embraced other, whereby Martineau reclaims the status of other as unique: the individual who has abilities that are considered deviant only because they are superior. She explains, "we see everything with different eyes — the chest of drawers - the walls—-the bookshelves, and the pattern of the rug" (Martineau 1844, p. 60). Here she reclaims the space of the sickroom, viewing the layout not in a clinical manner-as Thomson and others did-but through the invalid's subjective perspective, one that respects the imaginative as well as the physical.

She concludes this paragraph by suggesting the creative power of the invalid who spends her days reading: "We have been seeing the Northern Lights and icebergs: we have been watching for avalanches, or for the sun-rise from Etna, or gazing over the Pampas, or peering through the primeval forest; and fragments of these visions freshen the very daylight to us" (Martineau 1844, p. 60). Here Martineau challenges the heterotopia of deviation in depicting the invalid as not the cast-off or othered figure that encourages the illusion of health outside the sickroom but as a source of psychical insight that transcends the physical boundaries of the very sickroom through creative transformation. In this act of imaginative seeing, Martineau engages the objective-subjective struggle, thereby denying the ordered medical gaze the authority over physical space-neither body nor room. Martineau's text does not speak to recovery or death; rather, it reclaims the heterotopic nature of the sickroom as a site of validation by othering that which has been othered.

Like Martineau, Collins uses seeing and vision as a means of empowering the invalid. He does not experience Paris directly but observes it from his window, concluding, "the sights I watch with interest are those only which seem to refer in some degree to my own invalid position [ ... ] the only objects which I now notice attentively from my window, are, oddly enough, chiefly those which I should have missed altogether, or looked at with indifference, if I had occupied my bachelor apartment in the enviable character of a healthy man" (Collins [1856] 1875, p. 210). Although Maria Frawley views this passage as implied emasculation (Frawley 2004), I read the passage as expanding his visual astuteness beyond that of the healthy man; moreover, the visual sights are in reference to his locus, thereby positioning the invalid as the subject, not object, of seeing.

Collins's focus on observation translates to the creation of text itself and is done so in a way that turns the medical gaze on itself. "Laid Up in Lodgings" is divided into two sections: the first is set in his Paris sickroom, and the second is set in his London sickroom. The contrast between these two sickrooms reads, on the surface, as though Collins views the London sickroom as inferior to the Parisian one and conforms to the expectations set out in the medical guides about invalidism. He describes himself as "no longer a free agent; no longer a fanciful invalid with caprices to confide to the ear of the patient reader [ . . . ] I was a sick man with several things to discourse of; I am a sick man with only one topic to talk about" (Collins [1856] 1875, p. 217). This London room lacks the visual appeal, both inside and from his window, of the Parisian sickroom. Yet for all of Collins's claims that he cannot share multiple, whimsical experiences with the reader, his account of his London sickroom enjoys the same textual space and narrative as his Parisian sickroom. In other words, he does have multiple topics to share and quirky stories to tell, including accounts of his various maids. His conflicting claim exposes the perceived limitations imposed upon the invalid in Victorian Britain, and that Collins contests through the very act of writing his narrative.

While his observations are limited to his sickroom, they are perceptive in how they challenge the social view of invalidism. In describes his first maid, Collins reflects:

Number one is amazed by the spectacle of my illness, and always stares at me. If I fell ill one evening, went to a dispensary, asked for a bottle of physic, and got well on it the next morning; or, if I presented myself before her at the last gasp, and died forthwith in Smeary Street, she would, in either case, be able to understand me. However, an illness on which medicine produces no immediate effect, and which does not keep the patient always groaning in bed, is beyond her comprehension. (Collins [1856] 1875, p. 225).

Collins's description speaks not only to the nebulous nature of invalidism in Victorian England but also to the inability to comprehend chronic illness because it does not comply with objective accounts of illness, nor with the binary of healthy and ill. The maid, as representative of society as a whole, assumes 
invalidism is bound to a single space (the bed); Collins challenges this singular location of the invalid to reveal the nebulous nature of invalidism that defies medicine's attempts to categorize and contain it.

The linguistic element of heterotopias represents a threat without authority because it embodies that which undermines authority. The existence of multiple heterotopias, not just in terms of different physical sickrooms but also in different textual accounts of the sickroom, and all competing for the same space, negate the possibility of a single authority. "There is no pure form of heterotopia", notes Peter Johnson, "but different combinations, each reverberating with all the others. In a sense, they do not fully function except in relation to each other" (Johnson 2006, p. 84). This echoing is evident in both the direct and indirect engagement with other texts about the sickroom, from Bakewell's rejection of Domestic Medicine guides to Martineau's reimagining of the clinical sickroom to Collins's contrasting of the freeing Paris sickroom with the social assumptions of the London maids.

\section{Inverting Heterotopias: The Body as a Figurative Sickroom}

The problem with the multiple heterotopias Peter Johnson describes, however, is that they are not in harmony: "their relationships clash and create further disturbing spatio-temporal units" (Johnson 2006, p. 84). This new spatio-temporal unit is the heterotopia of the invalid body and how it was pathologized as part of the sickroom and texts about the sickroom. The invalid's body is spatially located within the sickroom and is what defines the sickroom; paradoxically, the sickroom is what defines the invalid. Mapping the heterotopic sickroom onto the body inverts the heterotopia in two ways: it presupposes the sickroom's existence before the existence of the invalid-the sickroom is prepared for the invalid to inhabit it-and it reveals the limitations of medicine in the act of classification. Temporally, invalidism represents a period of time but one that lacks clear definition: one could be an invalid for six months or six years, but inevitably the status of invalid will end, whether through recovery or death. Applying heterotopia as a spatial concept to the physical body returns the term to its medical origin and indicates a displacement about the body itself: more than merely diseased or suffering from illness, the invalid's body is displaced, housed outside its healthy location as active in the household. This displacement comes from the physical space of the sickroom, the textual representations of it, and the disconnect between them, whereby the individual experience of invalidism may not align with either medical or published personal accounts, yet the expectations of invalidism is that it should.

The transformation of the invalid's body into a space, one defined by the source space of the sickroom, is an act of power, one that presumes the docility of the body "that may be subjected, used, transformed and improved" (Foucault [1975] 1977, p. 136). Viewed as a physical space, like the sickroom, the body can be reorganized, conforming to the expectations of the medical community for compliance that "the individual [ ... ] be trained or corrected, classified, normalized, excluded, etc." (Foucault [1975] 1977, p. 191). Just as the sickroom was an appropriated space within the home, the term invalid was an appropriated word to delineate the sick body from the health body, steeped in the language of loss, lack, and difference and "constructed as a condition characterized not so much by specific disease or disorder but by one's loss of capacity for certain kinds of exertion" (Frawley 1997, p. 175). Victorian definitions of invalid were conceptual and included "one not strong or in good health [... ] An invalid is thus denominated from his wanting his ordinary share of health and strength" (Crabb 1844, p. 367) and "one who is weak, sickly, indisposed, or infirm" (Cooley 1861, p. 328). Loss was symbolically located in the absence of a medical definition of invalid in Victorian England: although discussed regularly in medical literature and medical handbooks, invalid as a term was not defined, suggesting a certain vagueness in how medicine viewed invalidism as broadly ill-health. The focus on treatment rather than definition or even symptoms (with the exception of defined diseases, like tuberculosis) was a product of viewing invalidism as a social marker, one that could go beyond medical diagnosis and treatment but grounded in a spatial location of the sickroom as a recovery space. As C. Home Douglas notes in his guide to travel for invalids, "Invalids may fairly be divided into three classes: those who are organically and hopelessly diseased; those who are 
functionally diseased; and those who, having no disease at all, have come abroad to relieve the ennui of country residence with a little fun and flirtation" (Douglas 1874, pp. 12-13). This last notion of escaping from a wearying life-as opposed to suffering from a diagnosed medical condition-reveals the blurred definition of invalid, one that could be medically diagnosed but could also be self- or socially-diagnosed. This blurring stems from the spatial location of the invalid in the sickroom that seeks to contain and define invalidism even as the term itself resists a single definition.

Thus, the space of the sickroom is mapped onto the invalid's body as a means of insisting upon definition and classification as tied to space itself. This spatial imagining of the body is a product of nineteenth-century medicine, whereby "the space of configuration of the disease and the space of localization of the illness in the body have been superimposed" (Foucault [1963] 1994, p. 3). Because invalidism is not a specific disease, the configuration is not of specific symptoms and locations within the body but rather a configuration of the sickroom space that confines the body to a definition. The physical confinement of the invalid's body to the sickroom was part of a transactional medicine, whereby "invalids were obliged to seek cures and in turn were permitted, even expected, to modify social obligations in order to fulfill this special task. In the language of the day, invalids had a lifelong obligation to improve-with all the nuances of the phrase intended" (Rothman 1994, p. 4). Obliged to pursue good health, invalids were allowed to occupy the space of the sickroom but that very space defined their social status. As a heterotopia of deviation, the invalid body houses that which is deemed abnormal, which is not just the physical symptoms of a disease but also the intellectual processing of that disease. Thus, the medical community saw the invalid's body as heterotopic, in need of marginalization and reorganization. Perhaps the most prominent example of this treatment of the invalid's body is the medical community's response to Martineau's book and broader view of invalidism: an anonymous review published in the British and Foreign Medical Review used Martineau's account to diagnose her as suffering from "nervous exhaustion", thereby inscribing the medical gaze on her body via her book (Winter 1995, p. 607). In doing so, he uses Martineau's own words against her, identifying not only Martineau but also her text as unhealthy, thereby aligning the body with language. In referencing Martineau's plea to visitors to tidy the sickroom before they leave to avoid a further disruption to the invalid's rest after said visit, the reviewer claims that such a request contradicts the aspirations of her text: "The world and its great parties are seen in a new and clearer light; they are looked at by the invalid with stoical philosophy [... ] And yet [ ... ] if a kind visitor, who has not the organ of order well developed, leaves the chairs awry, and the books unreturned to their shelves, all this lofty philosophy is overthrown, and its possessor cast into a state of miserable irritability" ("Life in a Sick-Room" 1844, pp. 478-79). The reviewer maps the disorder of the sickroom to a physical disorder for the invalid - though notably this order is caused by visitors and not the invalid, an inadvertent criticism of those who visit the space of the sickroom.

Diagnosis of Martineau through her text turns the textual sickroom into the bodily sickroom; such a shift reasserts medical authority by challenging the objective account of invalidism: "From being an authoritative statement it became the object of authoritative study; from being a body of knowledge it became a piece of contingent evidence" (Winter 1995, p. 608). It also assumes the body to be a "cultural artifact, fabricated both [in] the writing and reading of 'body texts', which include the interpretation aspects of spatial and temporal existence such as pain" (Fox 1997, p. 45). Knowledge of Martineau's body, then, is not discursively represented in her own text but in how it is read and written about in a medical text. This contemporary review is a reminder of how invalidism is defined by the space which the invalid occupies and reveals the reluctance of medicine to allow the invalid autonomy and identity within their own accounts of their space.

\section{Conclusions}

Heterotopias "are fundamentally disturbing places" through their modification of our familiar spaces (Johnson 2006, p. 84): the Victorian sickroom was the once-bedroom, both familiar and unsettling in its new role. As contrasted with the utopic ideal of health, the sickroom was a reminder of that 
which is not healthy and that which is physically demarcated but not easily defined; it also represented a contest space that is physical, textual, and corporeal. Those outside the sickroom sought to define it and control it because they did not want to be part of it; the act of othering served to distinguish health from illness and to reinforce the health of those outside of the sickroom. Thus, not only was health defined by not having the physical characteristics of ill health but was also understood through the physical space one occupied. At the same time, invalids inside the sickroom were compelled to reclaim the space as a means creating their own identity, not defined through the health of others but through their subjective experiences of illness. As a "disturbing place", the heterotopic sickroom was both troubling to those outside it and an act of disturbance by those within it. Invalidism by its very nature seeks to defy the clinical medical model, which is reliant upon a disassociation of disease from social context (Foucault [1963] 1994). Frawley describes it as "a mode of thought that shaped and a posture that expressed the way men and women conceptualized, experienced, and represented a wide range of afflictions" (Frawley 2004, p. 3). These individualized experiences of invalidism challenged definitions provided by the medical community and countered medical texts that sought to universalize the invalid's experience. For example, Dr. William Strange instructs in his manual: "The invalid will derive more benefit from a perusal of the work from beginning to end, than from dipping into it and endeavouring to find his own particular disorder portrayed" (Strange 1865, p. ix). Yet the accounts written by invalids indicate a uniqueness to their suffering, embodied in the rhetoric choice to use the first-person and to offer up a study of their conditions and their bodies on their own terms and in an attempt to contest the space of the sickroom.

The conflict, then, is that of the individual experience of the broadly-defined invalidism and the medical propensity to construct identity through the medical gaze, thereby further negating the individual experience of chronic suffering. If "an individual becomes in part [their] diagnosis", as Charles Rosenberg argues, and "diagnosis and prognosis, the intellectual and social framing of disease, has always been central to the doctor-patient relationship" (Rosenberg 1992, pp. xixi, xvii), then invalidism invalidates this relationship: the social framing is neglected, and diagnosis and prognosis are vague - neither good nor bad, but in a constant state of ambiguity. Invalidism, through its singularity of experience and cultural context, seeks to reject the medical gaze, yet the medical gaze constantly reasserts itself. By evoking the sickroom as heterotopia-both in the literal physical space and in the figurative space of the body-medical language relied on a false authority that further demeaned and restricted the invalid's identity. Invalid narratives that contested this space contested the very definition of invalidism as strictly medical, in an attempt to reclaim their identity. As constructed spaces, heterotopias "dissolve our myths and sterilize the lyricism of our sentences" (Foucault [1966] 1994, p. xviii), revealing their instability: "They are dangerous to the order of things, even as they are necessary to the establishment of order" (Dumm 2002, p. 43). In this way, invalidism proves the limitations of the medicalization of ill-health in the nineteenth century and contests an absolute and stable medical authority.

Funding: This research was funded by Misericordia University's faculty research grants committee.

Acknowledgments: The author would like to thank George Shea for helping to refine this article and fellow panelists and audience members at the "Diagnosis Literature I: Medical Narratives of Invalidism in the Nineteenth Century" panel at the Northeast Modern Language Association 2016 conference, at which a version of this paper was first presented.

Conflicts of Interest: The author declares no conflict of interest.

\section{References}

Ablow, Rachel. 2014. Harriet Martineau and the Impersonality of Pain. Victorian Studies 56: 675-97. [CrossRef] Bakewell, Robert Hall. 1857. Practical Hints on the Management of the Sick-Room. London: John Snow.

Byrne, Katherine. 2011. Tuberculosis and the Victorian Literary Imagination. Cambridge: Cambridge University Press. Cenzatti, Marco. 2008. Heterotopias of Difference. In Heterotopia and the City: Public Space in a Postcivil Society. Edited by Michiel Dehaene and Lieven de Cauter. New York: Routledge, pp. 75-85. 
Collins, Wilkie. 1875. Laid Up in Lodgings. In My Miscellanies. London: Chatto and Windus, pp. 199-229. First published in 1856.

Cooley, Arnold J. 1861. A Dictionary of the English Language. London and Edinburgh: W. and R. Chambers.

Crabb, George. 1844. English Synonyms, with Copious Illustrations and Explanations. New York: Harper.

Douglas, C. Home. 1874. Searches for Summer: Showing the Anti-Winter Tactics of an Invalid. Edinburgh and London: William Blackwood and Sons.

Dumm, Thomas L. 2002. Michel Foucault and the Politics of Freedom. New York: Rowman and Littlefield.

E.Q.S. 1845. Review of Life in the Sick-Room. Christian Examiner 38: 158-69.

Foucault, Michel. 1994. The Birth of the Clinic: An Archaeology of Medical Perception. New York: Vintage Books. First published in 1963.

Foucault, Michel. 1994. The Order of Things: An Archaeology of the Human Sciences. New York: Vintage Books. First published in 1966.

Foucault, Michel. 1977. Discipline and Punish: The Birth of the Prison. Translated by Alan Sheridan. London: Penguin Books. First published in 1975.

Foucault, Michel. 1984. Of Other Spaces: Utopias and Heterotopias. Translated by Jay Miskowiec. Architecture/Mouvement/Continuité. October. Available online: http://web.mit.edu/allanmc/www/foucault1. pdf (accessed on 12 February 2019).

Fox, Nick J. 1997. Is There Life after Foucault? Texts, Frames and Differends. In Foucault, Health, and Medicine. Edited by Alan Petersen and Robin Bunton. London: Routledge, pp. 31-50.

Frawley, Maria H. 1997. 'A Prisoner to the Couch': Harriet Martineau, Invalidism, and Self-Representation. In The Body and Physical Difference: Discourses of Disability. Edited by David T. Mitchell and Sharon L. Snyder. Ann Arbor: University of Michigan Press, pp. 174-88.

Frawley, Maria H. 2004. Invalidism and Identity in Nineteenth-Century Britain. Chicago: University of Chicago Press. Gardner, John. 1861. Household Medicine and Sick-Room Guide: A Familiar Description of Disease, Remedies, and Methods of Treatment, Diet, Etc. London: Smith, Edler, and Co.

Johnson, Peter. 2006. Unravelling Foucault's 'Different Spaces'. History of the Human Sciences 19: 75-90. [CrossRef] "Life in a Sick-Room". 1844. British and Foreign Medical Review 18: 472-81.

Mangion, Carmen M. 2015. 'To Console, to Nurse, to Prepare for Eternity': The Catholic Sickroom in Late Nineteenth-Century England. In Space, Place, and Gendered Identities: Feminist History and the Spatial Turn. Edited by Kathryne Beebe and Angela Davis. New York: Routledge, pp. 135-50.

Martineau, Harriet. 1844. Life in the Sick-Room: Essays. Boston: William Cosby.

Rosenberg, Charles E. 1992. Explaining Epidemics: And Other Studies in the History of Medicine. Cambridge: Cambridge University Press.

Rothman, Sheila M. 1994. Living in the Shadow of Death: Tuberculosis and the Social Experience of Illness in American History. New York: Basic Books.

Smith, Eric C. 2014. Foucault's Heterotopia in Christian Catacombs. New York: Palgrave.

Strange, William. 1865. The Restoration of Health, or the Application of the Laws of Hygiene to the Recovery of Health, Forming a Manual for the Invalid and a Guide in the Sick-Room. London: Longmans, Green, and Co.

Tankard, Alex. 2011. The Victorian Consumptive in Disability Studies. Journal of Literary and Cultural Disability Studies 5: 17-33. [CrossRef]

Thomson, Anthony Todd. 1845. The Domestic Management of the Sick-Room: Necessary, in Aid of Medical Treatment, for the Cure of Diseases, 2nd ed. London: Longman, Brown, Green, and Longmans. First published in 1841.

Winter, Alison. 1995. Harriet Martineau and the reform of the Invalid in Victorian England. The Historical Journal 38: 597-616. [CrossRef]

(C) 2019 by the author. Licensee MDPI, Basel, Switzerland. This article is an open access article distributed under the terms and conditions of the Creative Commons Attribution (CC BY) license (http://creativecommons.org/licenses/by/4.0/). 